\title{
Andreas Oksche \\ In honour of his ninetieth birthday
}

\author{
Klaus Unsicker $^{1}$
}

Published online: 12 April 2016

(C) Springer-Verlag Berlin Heidelberg 2016

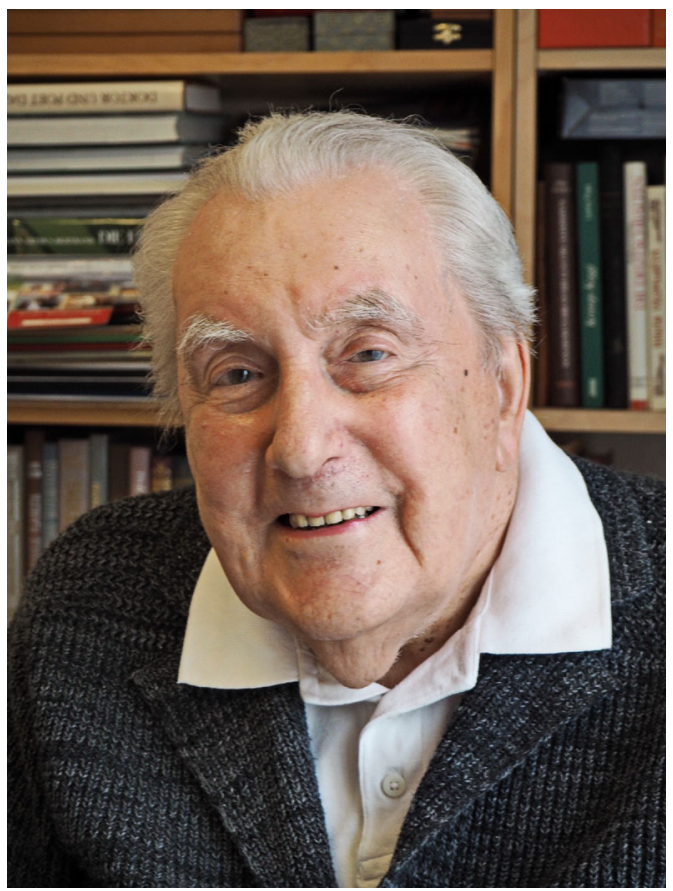

Andreas Oksche (by courtesy of Dr. Alexander Oksche)

Andreas Oksche Coordinating Editor of Cell \& Tissue Research from 1978 to 1995, and Co-Editor for the section "Neuroendocrinology" for many years, will celebrate his ninetieth birthday on 27 July 2016. We, the Editors, Springer

Klaus Unsicker

klaus.unsicker@anat.uni-freiburg.de

Institute of Anatomy and Cell Biology, Department of Molecular Embryology, University of Freiburg, Albertstr. 17,

79104 Freiburg, Germany
Nature Publishing Group, and many friends and former colleagues congratulate him on this occasion and wish him health and vitality for the years to come.

Andreas Oksche is known as an eminent figure in neuroendocrinology with a world-wide reputation, as a leading anatomist in Germany and beyond and as a prominent personality in national science policy. He was born in Riga, Latvia, and received his training in anatomy and neuroscience at the University of Marburg under the guidance of Professors Benninghoff and Niessing. His MD thesis on the "Organon frontale" of the grass frog established the foundation of his successful career in neuroendocrinology. Andreas Oksche's Habilitation addressed secretory features of glia, with special reference to the subcommissural organ, thereby expanding the list of cells with a secretory capacity in the brain and anticipating the functions of astroglia, which have only recently been analysed in detail. Following postdoctoral work with Ernst and Berta Scharrer, two prominent pioneers in neuroendocrinology and hypothalamic-pituitary neurosecretion, at the Albert Einstein College of Medicine, he moved to the University of Kiel, where, in the late 1940s, Wolfgang Bargmann had established a centre for research on hypothalamic neurosecretion. The concept of neurons having a secretory identity had been initially met with profound scepticism. Proceeding from the hypothalamus to the pineal gland and circumventricular organs, Andreas Oksche's contributions were essential to the broadening of the perception of the brain as having secretory capacities and of the neural-endocrine hybrid character of neurons. The discovery that such neuroendocrine cells could simultaneously act as photoreceptors and the elucidation of their fine structure was the culmination of the search for mechanisms underlying the regulation of 
neuroendocrine networks. Like many of those who had been under the mentorship of Wolfgang Bargmann, Andreas Oksche took a comparative anatomical approach exploiting the benefits of this strategy for interpolating functions from common structural features across animal phyla and classes.

In 1964, Andreas Oksche moved to the Anatomy Department at the University of Giessen, which he established as one of the world centres in pineal and extra-retinal photoreceptor research and which he chaired for 30 years. The "Giessen school of Neuroendocrinologists" was to become home over several decades to many international experts and generated offspring who spread throughout Germany and around the world.

Andreas Oksche not only shaped neuroscience by running a successful laboratory and guiding numerous young collaborators but he also strongly influenced science policy in Germany. He served the German Research Foundation (DFG), the major grant-giving national body, the Wissenschaftsrat, which dictates science policy in Germany, institutions such as the Göttingen Primate Centre, and, last but not least, the Anatomische Gesellschaft, whose president he was and which awarded him honorary membership. He was a cofounder of the European Pineal Study Group in the 1970s and became the first honorary president of the European Biological Rhythms Society in 2005. Since 1973, he has been a member of the Leopoldina, the National Academy of Science. In 2003, he became a recipient of the Leopoldina's Cothenius Medal, one of many prizes that he has received during his extensive career.

For almost 50 years, Andreas Oksche has served this journal, CTR, and its predecessor, the Zeitschrift für Zellforschung und mikroskopische Anatomie. CTR owes a large portion of its success to Andreas Oksche's devotion to the journal. We appreciate and thank him for his cooperation, advice and support.

Klaus Unsicker and the members of the CTR Editorial Board 